\title{
Ureteroscopy for management of ureteric calculi: Five years experience
}

\author{
in Erbil, Iraq
}

Received: $30 / 12 / 2015$

Accepted: 24/4/2016

\begin{tabular}{rr}
\hline Wishyar Jamal Al Bazzaz $*$ & Tarq Aziz Toma $* *$ \\
\hline Abstract &
\end{tabular}

Background and objective: Retrograde ureteroscope has recently gained a broaden indication for use in from diagnostic to a variety of disorders that occur in the upper urinary tract. This study aimed to review our five years experience with ureteroscopic management for ureteral stones and to compare our rates of efficacy and safety of ureteroscopy with other centers.

Methods: Review of 736 consecutive patients who underwent ureteroscopic procedures for the treatment of upper urinary tract problems between January 2010 and January 2015 was done in Erbil, Iraq. Out of those patients, 587 patients underwent a ureteroscopic procedure for the treatment of ureteric calculi. The studied variables were patients and stones characteristics, in addition to the mean operative time and mean hospital stay, the stone-free rate, and complication rates were also calculated.

Results: The overall success rate (complete stone clearance) in 587 patients was 550 patients (93.7\%). Mean operative time was 26.1 minutes and mean hospital stay was $<24$ hours. The overall complication rate was $12 \%$. The intra-operative complication rate was $3.2 \%$, the early postoperative complication rate was $8 \%$, and the late postoperative complication rate was $0.85 \%$.

Conclusion: Growing skill and experience of ureteroscopy will lead to a significant increase in the success rate and reduce complications.

Keywords: Semi-rigid ureteroscope; Pneumatic and laser lithotripter; Accessories; Instruments.

\begin{abstract}
Introduction
Minimal invasive techniques for management of upper ureteric calculi include extracorporeal shockwave lithotripsy (ESWL), ureteroscopy (URS), and percutaneous nephrolithotomy (PCNL). The choice of the procedure depends on three factors; stone-related factors (location, size, composition, duration of presence, and degree of obstruction), clinical factors (the patient's tolerance of symptomatic events, the patient's expectations regarding treatment outcome, associated urinary tract infection, solitary kidney, and abnormal ureteral anatomy), and technical factors (equipment available for treatment, and costs). Ureteroscopy is an examination of upper tract,
\end{abstract}

usually performed with an ureteroscope (endoscope) that is passed through the urethra, bladder, then directly into the ureter. It is one of the major developments in endourology. It had made a revolution in the management of the upper urinary tract disorders which before the advent of ureteroscope, was difficult proposition often resorting to complex radiological investigation and invariably open surgical procedures with its attendant morbidity and mortality. Therefore, the option of ureteroscopic stone extraction or fragmentation, although most patients require anesthesia, has become more attractive. $^{1}$ Ureteric stones should be treated in situ. Ureteroscopy may necessitate time for stone clearance

* Department of Urology, Rizgari teaching Hospital, Erbil, Iraq.

** Department of Urology, College of Medicine, Hawler Medical University, Erbil, Iraq. 
making repeated outpatient assessment and/or retreatment. ${ }^{2}$ It is used to treat upper urinary calculi, particularly those that are either unsuitable for ESWL (High-energy shockwaves capable of stone fragmentation) or refractory to that form of treatment. ${ }^{3}$ Other treatments include medical expulsive therapy (MET) for stone passage, antegrade ureteroscopy, laparoscopic and open ureterolithotomy. ${ }^{4}$ This study aimed to review our five years experience with ureteroscopic management for ureteral calculi.

\section{Methods}

Statistical analysis was carried out for the medical records of 736 consecutive patients who underwent ureteroscopic procedures for the treatment of upper urinary disorders during five years period starting from January 2010 to January 2015 at the Urology Department of Rizgary Teaching Hospital and two private hospitals (Sardam and Soran hospitals) in Erbil, Kurdistan, Iraq. The following parameters were considered in the analysis; age, sex, patients' symptoms, laboratory results, radiological findings, details about the calculus, and type of ureteroscope used and the energy source to fragment the calculi. The patients were subjected to preoperative work-up that included history taking, physical examination to detect anatomical or congenital abnormalities, urinalysis, colony count, urine for culture and sensitivity, $\mathrm{CBC}$ and coagulation profile, kidney function tests, and imaging procedures of KUB and US or (IVU) or non-enhanced computed tomography (CT urography). On the day of surgery, a prophylactic antibiotic was administered. Patients were sent to the operating room and put in the dorsal lithotomy position with legs supported in stirrups with minimal flex at the hips. The procedure was performed under general or spinal anesthesia. The equipments included ureteroscopy (semi-rigid ureteroscopy, Germany), fluoroscopy (C-arm fluoroscopy), video monitor, stone grasping baskets and forceps, lithoclast (Swiss lithoclast, Electro Medical Systems, Karl Storz) and laser (holmiumKarl Storz), and irrigation devices. Retrograde access to the upper urinary tract is usually obtained under endoscopic guidance and imaging. We used to place a safety guidewire. In cases where ureteral access was not possible, insertion of a ureteric stent was the option followed by ureteroscopy after 14 days. Continuous irrigation fluid (normal saline) maintaining a low-pressure system was the routine. Stones were extracted by grasping forceps or baskets under visualization. Stones that cannot be extracted directly were disintegrated using intracorporeal pneumatic lithotripter or laser. After completing the procedure, ureteral $\mathrm{JJ}$-stents inserted in patients who were at an increased risk of complications (e.g. residual fragments/large residual stone burden, bleeding, perforation, ureteral injury or obstructive uropathy) according to surgeon's judgment. Two weeks later, patients were readmitted to the theater either to remove stent or to redo ureteroscopy. Intraoperative complications of perforation, a migrating/ lost stone or avulsion were monitored and reported separately in the surgical notes. The submucosal tear was observed by direct visualization during the procedure, whereas avulsion and perforation were documented by intra-operative retrograde ureterorenography. The success of the procedure was also documented in terms of stone size and location of the stone. 


\section{Results}

Table 1 shows the indications for ureteroscopy. Age ranged from 21-68 years. The majority of the patients $(78 \%)$ were in the age group 30-40 (38.2) years. The total number of males undergoing the procedure was 330 patients $(56.2 \%)$, and the total number of females was 257 patients $(43.8 \%)$. The male to female ratio was 1.3:1. The most predominant symptom was renal colic which seen in 523 patients $(89.1 \%)$, macroscopic hematuria was seen in 424 patients $(72.2 \%)$, nausea and/or vomiting seen in 201 patients (34.2\%) and frequency of dysuria seen in 71 patients (12.1\%). Radiology studies included either combined KUB (kidney urinary bladder x-ray) and USG (ultrasonography) or I.V.U (intravenous urography) and in selected cases a non-contrast spiral CT (computed tomography). KUB visualized radio-opaque stones in $75.2 \%$ of patients. The upper and lower ureteric stones were demonstrated by Ultrasonography in 199 patients $(33.9 \%)$, and signs of obstruction observed in 475 patients $(80.9 \%)$.I.V.U was not performed for 112 patients (19.1\%) either due to the presence of renal failure or was deemed unnecessary in the case of calculus diseases where the stone size and location were adequately assessed by KUB and ultrasonography for planning ureteroscopy.I.V.U result was normal without filling defect and hydronephrotic changes in 32 patients $(6.7 \%)$, mildmoderate hydronephrosis seen in 423 patients $(89 \%)$, gross hydronephrosis observed in 83 patients $(17.4 \%)$, \&no or faint nephrogram seen in 47 patients (9.9\%) Non-Contrast CT-Scan (Native): non-contrast CT scan was used in 153 patients $(26 \%)$ as a stone was not seen by KUB, USG, and IVU or the patient had abnormal renal function test and contrast study could not be done. Ureteroscopy was done for 587 patients with calculus diseases of the ureter, 240 patients $(40.9 \%)$ presented on their right side, 329 patients $(56 \%)$ presented on the left side, and 18 patients $(3 \%)$ presented on both sides (Bilateral). Regarding the location of the calculus, $68.7 \%$ of calculi were in the lower ureter, $14.7 \%$ were in the mid ureter, and $16.6 \%$ were in the upper ureter. The size of the calculus ranged from 5-20 $\mathrm{mm}$. The most common size of the calculi was less than $10 \mathrm{~mm}$ which was observed in 464 patients $(79 \%)$.

Table 1: Distribution of sample by indication for ureteroscopy.

\begin{tabular}{lcc}
\hline Indications & No. & $\%$ \\
\hline *Ureteric stones & 557 & 75.67 \\
Renal stones & 70 & 9.5 \\
Diagnostic & 32 & 4.34 \\
Stricture alone & 25 & 3.4 \\
*Post-ESWL & 21 & 2.85 \\
Puj obstruction & 14 & 1.9 \\
*Ureteric stones associated with ureteric stricture & 9 & 1.22 \\
Migrated stent & 7 & 0.95 \\
Ureteric mass & 1 & 0.13 \\
Total & 736 & 100 \\
\hline
\end{tabular}

PUJ= pelvic ureteric Junction

*Note: Our study included 587 patients who underwent ureteroscopic procedures for treatment of ureteric calculi which included: Ureteric stone (557 patients, $75.67 \%)$, post-ESWL (21 patients, $3.58 \%$ ), and ureteric stone associated with ureteric stricture (9 patients, $1.53 \%$ ). 


\section{Success rate:}

The overall complete stone clearance (success rate) was accomplished in 550 out of 587 patients (93.7\%). Table 2 shows that the highest success rate was among patients with lower ureteric stones (96\%), compared with $83 \%$ for the upper ureteric stones $(P<0.001)$. No significant differences in the success rate were detected when the stones were small $(<10 \mathrm{~mm})$ compared with the bigger ones $(P=0.348)$. Table 3 shows no significant differences in the success rates of patients with small stones and patients with big stones (less vs. more than $10 \mathrm{~mm}$ ). This applies to lower ureteric stones $(P=0.9)$, mid-ureteric stones $(P=0.84)$, and upper ureteric stones $(P=0.95)$.

Table 2: Success rate by stone location and size of the calculus.

\begin{tabular}{lccccccc}
\hline & \multicolumn{2}{c}{ Success } & \multicolumn{2}{c}{ Failure } & \multicolumn{2}{c}{ Total } & \multirow{2}{*}{ value } \\
& No. & $\%$ & No. & $\%$ & No. & $\%$ & \\
\hline Stone location in ureter & & & & & & \\
Lower & 388 & 96 & 15 & 4 & 403 & 100 & \\
Mid & 81 & 94 & 5 & 6 & 86 & 100 & $<0.001$ \\
Upper & 81 & 83 & 17 & 17 & 98 & 100 & \\
Stone size & & & & & & & \\
$<10 \mathrm{~mm}$ & 437 & 94 & 27 & 6 & 464 & 100 & 0.348 \\
$\geq 10 \mathrm{~mm}$ & 113 & 92 & 10 & 8 & 123 & 100 & \\
Total & $\mathbf{5 5 0}$ & $\mathbf{9 3 . 7}$ & $\mathbf{3 7}$ & $\mathbf{6 . 3}$ & $\mathbf{5 8 7}$ & $\mathbf{1 0 0}$ & \\
\hline
\end{tabular}

Table 3: Success rates of patients with small stones compared with rates of patients with big stones in different locations of the stones.

\begin{tabular}{|c|c|c|c|c|c|c|c|}
\hline \multirow{2}{*}{$\begin{array}{l}\text { Stone } \\
\text { level }\end{array}$} & \multicolumn{2}{|c|}{$<10 \mathrm{~mm}$} & \multicolumn{2}{|c|}{$\geq 10 \mathrm{~mm}$} & \multicolumn{2}{|c|}{ Total } & \multirow{2}{*}{$P$ value } \\
\hline & No. & $\%$ & No. & $\%$ & No. & $\%$ & \\
\hline \multicolumn{8}{|c|}{ Lower ureteric stones } \\
\hline Success & 332 & 96.2 & 56 & 96.6 & 388 & 96.3 & \\
\hline Failure & 13 & 3.7 & 2 & 3.4 & 15 & 3.7 & 0.9 \\
\hline Total & 345 & 100 & 58 & 100 & 403 & 100 & \\
\hline \multicolumn{8}{|c|}{ Mid-ureteric stones } \\
\hline Success & 52 & 94.5 & 29 & 93.5 & 81 & 94.2 & \\
\hline Failure & 3 & 5.5 & 2 & 6.5 & 5 & 5.8 & 0.84 \\
\hline Total & 55 & 100 & 31 & 100 & 86 & 100 & \\
\hline \multicolumn{8}{|c|}{ Upper ureteric stones } \\
\hline Success & 53 & 82.8 & 28 & 82.4 & 81 & 82.7 & \\
\hline Failure & 11 & 17.2 & 6 & 17.6 & 17 & 17.3 & 0.95 \\
\hline Total & 64 & 100 & 34 & 100 & 98 & 100 & \\
\hline
\end{tabular}


As we described before, the overall complete stone clearance was $93.7 \%$. Partial stone removal was performed in 11 patients $(1.9 \%)$; redo ureteroscopy was done for four of them, and seven patients passed the fragments spontaneously. Stone migration was seen in 13 patients $(2.2 \%)$ and all of them were stented, 11 of them sent to ESWL \& in two of them, the stone was removed following removal of $\mathrm{JJ}$ stent. Stricture associated with ureteric stone was seen in nine patients $(1.5 \%)$. In three of them, a guide wire was placed and stone crushing was done after visual dilatation, then JJ stented placed. For six of them, visual dilatation was difficult and only JJ stent was placed, following 6-8 weeks redo ureteroscopy was performed and the stone was removed. (Note: Balloon dilator is not available in our center). Significant bleeding occurred in one patient $(0.2 \%)$ due to poor vision and inability to pass the guide wire the procedure failed. This failure didn't lead to any unwanted effect in the postoperative period, and redo ureteroscopy was done successfully four weeks later. Open surgery conversion was done due to a large ureteral perforation in two patients $(0.34 \%)$, and lower ureteric avulsion in one patient $(0.17 \%)$. The overall of stent indwelling performed in 199 patients $(34 \%)$ ureteral stent was left in place for 2-8 weeks according to the cases. Stent placement after the procedure was based on the presence of ureteral injury, large residual stone burden, stricture, marked edema at the site of impacted stone, stone migration, solitary kidney, and renal insufficiency. Mean operative time was 26.1 minutes, and mean hospital stay was $<24 \mathrm{~h}$.

\section{Complications:}

Regarding complications (Table 5), the total intra-operative and postoperative complications were found in 71 patients (12\%). Intraoperative complication: A long segment ureteric avulsion occurred in one patient $(0.17 \%)$. This occurred very early in our series because at that time we had less experience and limited equipments. This was a case of a right-sided impacted lower ureteric calculus about $14-15 \mathrm{~mm}$ in size for which ureteroscopy attempted. The patient underwent reconstructive surgery in the form of Boari flap. Ureteric perforation occurred in four patients $(0.68 \%)$, all cases recognized immediately, two of them underwent open surgery, and for two of them JJ stent placed without postoperative complication, and minor mucosal abrasion occurred in 13 patients $(2.21 \%)$ also recognized immediately, JJ stent placed with no further treatment required. Postoperative complications included early

Table 4: Final outcome of ureteroscopic lithotripsy.

\begin{tabular}{lcc}
\hline Outcome & No. & $\%$ \\
\hline Complete stone clearance & 550 & 93.7 \\
Partial stone removal & 11 & 1.9 \\
Stone migration & 13 & 2.2 \\
Stricture and ureteric stone & 9 & 1.5 \\
Significant bleeding & 1 & 0.2 \\
Open surgery conversion & 3 & 0.5 \\
Total & 587 & 100 \\
\hline
\end{tabular}


and late postoperative complications, early postoperative complications included: Fever $(3.23 \%),(2.72 \%)$, and persistent hematuria $(2.05 \%)$. Late postoperative complications included: stricture $(0.51 \%)$ and transient $\mathrm{V}-\mathrm{U}$ reflux $(0.34 \%)$.

\section{Discussion}

Hampton Young performed the first ureteroscopy in 1912 in an infant with massively dilated ureters using a cystoscopy, which advanced easily to the renal pelvis. ${ }^{5}$ Marshall described fiberoptic ureteroscopy in 1964 and the first build ureteroscopy was reported in $1979 .{ }^{6}$ The new generation small bore rigid and semi rigidfiberopticureteroscopes have become integral to the modern management of ureteric calculi. Open ureterolithotomy is rare except in a select subgroup of patients i.e. those with complex calculus disease or associated with anatomic abnormalities. Ureteroscopy has become as effective as open surgery with little attendant morbidity. ${ }^{7}$ Early intervention and relief of an obstruction preclude the development of renal obstructive complications. Also with modern lifestyles and demands of the place, the patients prefer rapid diagnosis and early management of their problem. Ureteroscopy has traditionally constituted the favored approach for surgical approach of ureteral stones, with the development of smaller caliber semirigid and flexible ureteroscopes and the introduction of improved instrumentation, including laser and pneumatic lithotripter. ${ }^{8}$ Ureteroscopy has evolved into a safer and more efficacious modality for treatment of stones in all locations in the ureter with increasing experience worldwide. Growing skill and experience of the ureteroscopy led to significant increase in success rate and reduce complications. Recently overall complete stone free rate remarkably high at $81 \%$ to $94 \%$ depending on stone location with the vast majority of patients rendered stone free in a single procedure. ${ }^{9}$ The study in our center (Department of Urology in Erbil//raq) revealed that the overall stone-free rates were $93.7 \%$. The success rate for stone clearance for the lower ureteric stone was $96.3 \%$, for mid ureteric stone dropped to around $93.7 \%$, and for the upper ureteric stone dropped more around $82.65 \%$. Currently, the overall intra-operative and postoperative complications of ureteroscopy have been significantly reduced to $3-20 \% .{ }^{10-12}$ These complications include ureteral avulsion, ureteral perforation, minor mucosal abrasion, significant bleeding, renal colic, urosepsis, stricture, and transient v-u reflux. In our study, intra-operative and postoperative complications were found in 71 patients $(12 \%)$. Ureteral avulsion is a potentially serious complication that should always be

Table 5: Frequency of intra-operative, and post-operative complications (71 patients $12 \%$ ).

\begin{tabular}{|c|c|c|c|c|}
\hline \multicolumn{3}{|l|}{ Complications } & \multirow{2}{*}{$\frac{\text { Complications }}{1}$} & \multirow{2}{*}{$\frac{\text { No. }}{1}$} \\
\hline \multirow{4}{*}{\multicolumn{2}{|c|}{$\begin{array}{l}\text { Intra-operative complications } \\
19 \text { patients }(3.2 \%)\end{array}$}} & $\begin{array}{c}\text { Complete ureteric avulsion of } \\
\text { lower segment }\end{array}$ & & \\
\hline & & Ureteric perforation & 4 & 4 \\
\hline & & Minor ureteric mucosal abrasion & 13 & 13 \\
\hline & & Significant bleeding & 1 & 1 \\
\hline \multirow{5}{*}{$\begin{array}{l}\text { Postoperative } \\
\text { complications }\end{array}$} & \multirow{3}{*}{$\begin{array}{l}\text { Early complications } \\
47 \text { patients }(8 \%)\end{array}$} & Persistent hematuria & 12 & 12 \\
\hline & & Renal colic & 16 & 16 \\
\hline & & Fever/urosepsis & 19 & 19 \\
\hline & \multirow{2}{*}{$\begin{array}{l}\text { Late complications } \\
5 \text { patients }(0.85 \%)\end{array}$} & Stricture & 3 & 3 \\
\hline & & Transient V-U reflux & 2 & 2 \\
\hline
\end{tabular}


taken into account when performing such procedure. The first cases were reported by Hart in 1967 and Hodge in 1973, ${ }^{13,14}$ both complications occurred after difficult manipulation of a ureteral stone and prolonged procedure. Growing skill and experience of ureteroscopy led to a significant decrease in development of such complication to less than $0.5 \% .^{15}$ In our study, avulsion occurred in only one patient $(0.17 \%)$. CROES URS Global Study $($ CROES $=$ The clinical research office of the endo-urological study) was a prospective, observational, multicenter study conducted in 32 countries between Jan.2010 and Oct.2012, which included low volume center and high volume center. ${ }^{15}$ Which reveals patient baseline characteristic, operative factors and postoperative outcomes of URS-treated patients at low and high volume centers were compared. We like to compare CROES URS Global study with our study (in the department of Urology in Erbil/Iraq) (Table 6). These findings were matched up to that published study, which shows overall stone-free rates and complication rate almost similar. In $\mathrm{M}$. El-Qadhi 2013 outcome of ureteroscopy for the management of distal ureteric calculi: 5-years' experience showed an incidence of $79.4 \%$ for the initial stone-free status following a single treatment and $95.9 \%$ for the overall stone-free rate, which is comparable to our result. ${ }^{16}$ In Weimin Yu, Fan Cheng et al. 2014 retrograde ureteroscopic treatment for upper ureteral stones: A 5-Year Retrospective Study Overall, the stone-free rate was $90.4 \%$, the mean operative duration was $41.2 \pm 10.7$ minutes, in our study the overall success rate was $93.7 \%$ and mean operative time was 26.1 minutes. ${ }^{17}$ Ureteral stenting following uncomplicated URS is optional: several randomized prospective studies published since the 1997 AUA guideline document has demonstrated that routine stenting after uncomplicated URS may not be necessary. ${ }^{18,19}$ It is well documented that ureteral stenting is associated with bothersome lower urinary tract symptoms and pain that can albeit temporarily, alter the quality of life ${ }^{20,21}$ besides, their complications associated with ureteral stenting, including infection, breakage, encrustation, and obstruction. Moreover, ureteral stents add some expense to the overall ureteroscopic procedure, and unless a pull string is attached to the distal end of the stent, secondary cystoscopy is

Table 6: Comparison of our result with CROES URS Global Study.

\begin{tabular}{|c|c|c|c|c|}
\hline Characteristics & & $\begin{array}{l}\text { Low Volume } \\
\text { Centre }\end{array}$ & $\begin{array}{l}\text { High Volume } \\
\text { Centre }\end{array}$ & Our Centre \\
\hline Age, Years, Mean & & 49.9 & 48.3 & 38.2 \\
\hline \multirow[t]{2}{*}{$\operatorname{Sex}(\%)$} & Male & 63.7 & 66.7 & 56.3 \\
\hline & Female & 36.3 & 33.3 & 43.7 \\
\hline Total number of patients & & 1329 & 6860 & 587 \\
\hline Mean of operation time, min & & $48.3(30.2)$ & $39.6(23.2)$ & $41.2(26.1)$ \\
\hline Mean of Hospital stay, hours & & $<48$ & $<12$ & $<24$ \\
\hline Overall stone free rates (\%) & & 86.3 & 93.9 & 93.7 \\
\hline \multirow{5}{*}{$\begin{array}{l}\text { Intra-operative } \\
\text { complications (\%) }\end{array}$} & Uneventful & 91.1 & 94.8 & 87.75 \\
\hline & Ureteral avulsion & 0.5 & 0.04 & 0.17 \\
\hline & Ureteral perforation & 2.3 & 0.8 & 0.68 \\
\hline & Ureteric mucosal abrasion & 3.6 & 2.2 & 2.38 \\
\hline & Significant Bleeding & 2.5 & 0.9 & 0.17 \\
\hline \multirow{2}{*}{$\begin{array}{l}\text { Total postoperative } \\
\text { complications (\%) }\end{array}$} & Early Complication & 3.6 & 2.2 & 8 \\
\hline & Late Complication & 0.9 & 0.3 & 0.85 \\
\hline
\end{tabular}


required for stent removal. ${ }^{22}$ In our center, the overall rate of stent indwelling was $34 \%$ and left in place for 2-8 weeks according to the cases and postoperative situation. Stent placement after the procedure was based on the following conditions: ureteral injury, large residual stone burden, stricture, marked edema at the site of impacted stone, stone migration, solitary kidney, and renal insufficiency.

\section{Conclusion}

The current study of ureteroscopic management for ureteric calculi displayed an outcome and complications comparable with other recent reports. We think that handling of the stone(s) is better to be judged on an individual surgical basis. Improvement in skills and experience will hopefully lead to significant progress in the success rate and decreased complications.

\section{Conflicts of interest}

The authors report no conflicts of interest.

\section{References}

1. Preminger GM, Tiselius HG, Assimos DG, Alken $P$, Buck AC, Gallucci M, et al. Guideline for the management of ureteral calculi. European urology 2007; 52(6):1610-31.

2. Segura JW. Ureteroscopy for lower ureteral stones (editorial). Urology1993; 42:356-7.

3. Stefano CM, Picozzi, Marenghi C, Casellato S, Ricci C, Gaeta M, et al. Management of ureteral calculi and medical expulsive therapy in emergency departments. J Emerg Trauma Shock 2011; 4(1):70-6.

4. Segura JW, Preminger GM, Tiselius HG, Assimos DG, Alken P, Buck C, et al. EAU/AUA nephrolithiasis guideline. American Urological Association Education and Research/European Assoc. of Urology; 2007.

5. Meldrum KK, Mathews R, Gearhart JP. Hugh Hampton Young: a pioneer in pediatric urology. J Urol 2001; 166(4):1415-17.

6. Marshall VF. Fiber Optics in Urology. J Urol 1964; 91:110-14.

7. Ather $\mathrm{MH}$, Paryani J, Memon A, Sulaiman MN. A 10-year experience of managing ureteric calculi: changing trends towards endourological intervention-is there a role for open surgery? BJU Int 2001; 88(3):173-7

8. Francesca F, Scattoni V, Nava L, Pompa P, Grasso M, Rigatti P. Failures and complications of transurethral ureteroscopy in 297 cases: conventional rigid instruments vs. small caliberssemirigidureteroscopies. Euro Urol 1995; 28:112.

9. Harmon WJ, Sershon PD, Blute ML, Patterson DE, Segura JW. Ureteroscopy: current practice and long-term complications. J Urol 1997; 157 (1):28-32.

10. Johnson DB, Pearle MS. Complications of ureteroscopy. UrolClin North Am 2004; 31:157.

11. Mugiya S. Guidelines on urolithiasis: update of diagnosis and treatment. Hinyokika Kiyo 2012; 58 (12):703-6.

12. Geavlete P, Georgescu D, Niţă G, Mirciulescu V, Cauni V. Complications of 2735 retrograde semirigid ureteroscopy procedures: a singlecenter experience. J Endourol 2006; 20(3): 179-85.

13. Hart JB. Avulsion of distal ureter with dormia basket. J Urol 1967; 97(1):62-3.

14. Hodge J. Avulsion of a long segment of ureter with Dormia basket. Br J Urol 1973; 45(3):328.

15. Perez Castro E, Osther PJ, Jinga V, Razvi $\mathrm{H}$, Stravodimos KG, Parikh K, et al. Differences in ureteroscopic stone treatment and outcomes for distal, mid-, proximal, or multiple ureteral locations: the Clinical Research Office of the Endourological Society ureteroscopy global study. Eur Urol 2014; 66(1):102-9.

16. M El-Qadhi. Outcome of ureteroscopy for management of distal ureteric calculi: 5-year experience. African Journal of Urology 2015: 21(1):67-71.

17. Yu W, Cheng F, Zhang $X$. Reterograde ureteroscopic treatment for upper ureteral stone: a 5 year reterospective study. J Endourol 2010; 24:1753-7.

18. Byrne RR, Auge BK, Kourambas J, Munver R, Delvecchio F, Preminger GM. Routine ureteral stenting is not necessary after ureteroscopy and ureteropyeloscopy: a randomized trial. J Endourol 2002; 16:9.

19. Chen YT, Chen J, Wong WY, Yang SS, Hsieh $\mathrm{CH}$, Wang CC. Is ureteral stenting necessary after uncomplicated ureteroscopic lithotripsy? A prospective, randomized controlled trial. J Ural 2002; 167:1977.

20. Borboroglu PG, Amling CL, Schenkman NS, Monga M, Ward IF, Pipeer NY, et al. Ureteral stenting after ureteroscopy for distal ureteral calculi: a multi-institutional prospective randomized controlled study assessing pain outcomes and complications. J Urol 2001; 166:1651.

21. Denstedt JD, Wollin TA, Sofer M, Nott L, Weir M, D'A Honey RL. A prospective randomized controlled trial comparing nonstented versus stented ureteroscopic lithotripsy. J Urol 2001; 165:1419.

22. Damiano R, Autorino R, Esposito C, Cantiello F, Sacco R, de SioM, et al. Stent positioning ureteroscopy for urinary calculi Eur Urol 2004; 46:381. 